\title{
The Role of History of Mathematics in Mathematics Education
}

\author{
Renaud Chorlay and Wann-Sheng Horng
}

\section{Report}

At the ICME 2012 Conference, history of mathematics (HM) in maths education was specifically discussed in several contexts: one of the 37 Topic Study Groups (chaired by W.S. Horng and R. Chorlay); one discussion group on "Uses of History of Mathematics in School (Pupils aged 6-13)" (organised by B. Smestad); one regular lecture on "History, Application, and Philosophy of Mathematics in Mathematics Education: Accessing and Assessing Student's Overview \& Judgment" (by U. Jankvist); and one general presentation of The HPM international study group, among the organizations affiliated with the ICMI. A parallel TSG dealt with the history of mathematics teaching and learning (chaired by $\mathrm{K}$. Bjarnadottir and F. Furinghetti).

Eleven talks and fourteen posters were presented in the context of TSG 20, with participants from (nearly) all continents; unfortunately, the African continent was not represented. The TSG was a great success if success is to be measured by attendance.

Being of a multi-faceted nature, the topic was addressed from a great variety of viewpoints, which testifies to the richness of our field. Our goal here is not to

Organizers Co-chairs: Renaud Chorlay (France), Wann-Sheng Horng (Taiwan); Team Members: Hyewon Chang (Korea), Kathy Clark (USA), Abdellah El Idrissi (Moroco), Manfred Kronfellner (Austria); Liaison IPC member: Evelyne Barbin.

R. Chorlay $(\square)$

ESPE, Paris, France

e-mail: renaud.chorlay@espe-paris.fr

W.-S. Horng

National Taiwan Normal University, Taipei, Taiwan

e-mail: horng@math.ntnu.edu.tw

(C) The Author(s) 2015

S.J. Cho (ed.), The Proceedings of the 12th International Congress

on Mathematical Education, DOI 10.1007/978-3-319-12688-3_45 
summarize the talks (which are still available on-line at http://www.icme12.org/) but to stress this variety of viewpoints and research perspectives.

Research in the history of mathematics was represented by A. Cauty's talk on Aztec calendars, providing the rest of the community with fresh material for future, more teaching-oriented work. At the other end of the spectrum, several innovative teaching or training experiments were presented and discussed: a course for undergraduate students, with a focus on the role of mathematics in European culture (J. Wanko); an undergraduate course on propositional logic and the meaning of "if-then" statements, emphasizing student work on original sources (J. Lodder); a course designed for newly qualified teachers, with an emphasis on the role of HM as a means to foster mathematical content knowledge (S. Lawrence); a course on the history of mathematics for pre-service teachers in Norway, with a focus on the interactions between historical content knowledge, image of mathematics, and attitude toward the inclusion of HM in teaching (B. Smestad).

Finding the right tools (be they conceptual, or quantitative) to describe, analyze and assess teaching practices is another endeavour that calls for further research. These questions are by no means specific to the HPM community, and it is wellworth investigating the extent to which shared tools are relevant in an HPM context. Along this line of research, M. Alpaslan presented his on-going doctoral work on the assessment of a pre-service teacher-training course in HM in Turkey, with a view to improving its design in a context of institutional reform. U. Jankvist presented a joint work (with R. Mosvold, J. Fauskanger, and A. Jakobsen) on the MKT framework (Mathematical Knowledge for Teaching), and argued for its usefulness both as an analytical tool and as a means of communication with the math-education community at large.

Four case-studies were presented, which used specific historical texts to address didactical/epistemological research questions. The role of visualization in proofs was studied on the base of Archimedes' "mechanical proof" of the theorem on the volume of the sphere (M. del Carmen Bonilla); CABRI 3D was used as a visualization tool. S. Xuhua argued that several justifications for algorithms in the multiplicative theory of fractions that can be found in the Chinese classic The Nine Chapters could improve students' understanding of the standard rules, and help fight well-known systematic errors. T. Kjeldsen reported on an experiment conducted at high-school level, in which students were asked to make sense and compare two historical texts bearing on the notion of function (Euler, Dirichlet); among other effects, this unusual task was shown to help make "meta discursive rules" more explicit. Finally, A. Michel-Pajus presented a collection of algorithmic texts - some well-known, some excitingly new - and studied them from an epistemological and comparative perspective; the algorithms were studied both in terms of expression (algorithmic texts, in a semiotic and instrumental context), and justification.

It should be stressed that in the ICME context, the TSG on HM in mathseducation attracts many newcomers to the field of HPM, thus challenging members of the HPM community to make their "common culture" and their quality requirements more explicit. For instance, the fact that most of us stress the 
importance of the use of original sources may have come as a surprise to some; even without considering use in the classroom, the fact that original sources are available (availability being highly dependent on language) is not always so well known. When original sources are considered, working with them does require some know-how. We hope this TSG was instrumental in raising awareness on these aspects; we were pleased to see that many participants, including newcomers, could attend the HPM meeting in Daejeon (16-20 July 2012).

The chairpersons would very much like to thank all those who helped organize this TSG, in particular the members of the "team": Hyewon Chang, Kathy Clark, Abdellah El Idrissi, and Manfred Kronfellner; and, Evelyne Barbin, who acted as liaison with the IPC.

Open Access This chapter is distributed under the terms of the Creative Commons Attribution Noncommercial License, which permits any noncommercial use, distribution, and reproduction in any medium, provided the original author(s) and source are credited. 